\title{
Appendix Tubular Carcinoid
}

National Cancer Institute

\section{Source}

National Cancer Institute. Appendix Tubular Carcinoid. NCI Thesaurus. Code C43565.

A neuroendocrine tumor that arises from the appendix. It does not show the

morphologic characteristics of typical carcinoid tumors (neoplastic cells forming solid nests). In contrast, the tumor cells form small discrete tubules. 